\title{
DISTÚRBIOS \\ GLOBAIS DO \\ DESENVOLVIMENTO
}

Francisco B. Assumpção Jr.

\section{INTRODUÇAOO}

( onsiderando-se que o diagconhecimento integral do paciente", o diagnóstico desses distúrbios, é, por si só extremamente complexo, uma vez que deve considerar a incidência de diversas patologias em um organismo em crescimento e evoluçào.

Para seu estabelecimento, podemos ter dois critérios. Um individual, no qual o profissional procura reunir todos os elementos conseguidos através da anamnese e exames, chegando a uma solução. Essa formulaçào diagnóstica é extremamente freqüiente entre nós, principalmente considerando que pertencemos a um terceiro mundo carente de recursos económicos e pessoais e também ao fato de o psiquiatra da infância, pelas próprias características da especialidade, nào ter o hábito de pensar procurando englobar conhecimentos provenientes de outras especialidades médicas, ficando, no mais das vezes, restrito ao pensamento psiquiátrico tradicional, difícil de ser transportado totalmente à compreensão da ctiança.

Outro critério, é o diagnóstico realizado coletivamente, de modo compreensivo, no qual podem ser visualizadas a situaçào atual do paciente e as repercussòes futuras de seu problema.

Esse modelo também é de difícil aplicaçào em Psiquiatria da Infância, uma vez que esta não apresenta uma nosografia bastante estabelecida e aceita, ficando os quadros clínicos dependentes da escola psiquiátrica a que o profissional se filia e, portanto, sendo bastante difícil sua aceitaçào e compreensào por parte de outros médicos filiados a padròes de pensamento diferentes.

A tentativa de padronização, através das escalas: Classificaçào Internacional das Doencas Mentais (CID) ou Manual de Diagnóstico e Estatística de Distúrbios Mentais (DSM), reflete simplesmente a mudança para uma visào

Doutor em Psicologia pela PUC/USP; professor livre-docente do Departamento de Psiquiatria da Faculdade de Medicina da USP; Diretor do Serviço de Psiquiatria da Infância e da Adolescência do Hospital das Clínicas da FMUSP. 
mais pragmática e imediatista, decorrente do próprio momento em que nos encontramos. Isso porque, embora apoiadas em um contexto teórico dito "fenomenológico", esse termo é utilizado de formas diferentes. Conforme Parnas (1991), para os psiquiatras de língua inglesa, a palavra fenomenologia é semelhante a psicopatologia descritiva e se refere a descriça de sintomas e sinais das doenças psiquiátricas. Isso proporciona, em meu modo de ver, muitas vezes, um empobrecimento no pensamento psiquiátrico que passa a desconsiderar a vivência da doença, a qual se apresenta de forma bastante diversa em cada paciente.

Com essas duas visoees, complementares, porém, com perspectivas tão diversas, estruturam-se as principais classificaçòes atuais em Psiquiatria Infantil. Baseadas em uma psicopatologia eminentemente descritiva, linear e sem preocupações com processos compreensivos, tentadas a aproximar a semiologia psiquiátrica da semiologia médica tradicional, encontram-se os CID 10 e o DSM IV. Fundamentada em toda sua tradição compreensiva, com influências marcantes das escolas psicodinâmicas, temos a Classificaçào Francesa dos Distúrbios Mentais (Misés, 1990), pouco conhecida e pouco utilizada em nosso meio.

\section{A VISÃO ATUAL DO CONCEITO DE DISTÚRBIO GLOBAL DE DESENVOLVIMENTO}

Os Transtornos Globais de Desenvolvimento são hoje considerados como decorrentes de etiologias múltiplas (Gilberg,1990). Conforme já dissemos anteriormente, eles sào caracterizados por um déficit social, visualizado pela inabilidade em relacionar-se com o outro, usualmente combinado com déficit de linguagem e alterações de comportamento (Gilberg,1990). Em alguns quadros específicos, podemos ainda observar retardo no desenvolvimento neuropsicomotor ou mesmo perda de funções anteriormente adquiridas.

Pensando-se mais especificamente o Autismo, o mais estudado dos Transtornos Globais de Desenvolvimento, encontramos diversos autores, entre os quais Wing (1988), que apresentam a noção de Autismo como um específico sintomatológico, dependente do comprometimento cognitivo. Essá abordagem reforça a tendência de tratar o Autismo não mais como uma entidade única, mas como um grupo de doenças, embora traga implícita também a noção de Autismo relacionada primariamente a déficits cognitivos.

Dessa maneira, torna-se de extrema dificuldade a construção do diagnóstico Autismo, uma vez que, conforme dissemos até o presente, ele engloba um grande número de patologias diferentes, bem como uma concepção teórica de grande influência nesse pensar. 
O diagnóstico diferencial do Autismo Infantil é de extrema dificuldade e também passível de uma série de controvérsias, uma vez que engloba, dentro dos atuais conceitos, uma gama bastante variada de doenças, com diferentes quadros clínicos, que tem como fator comum básico o sintoma autístico, ou seja, o isolamento.

Revisando seu próprio conceito de Autismo Infantil, Kanner, em 1968, referia-se às falhas em se produzir evidências neurológicas, metabólicas ou cromossômicas no Autismo Infantil. Ao mesmo tempo, frisava a importância do diagnóstico diferencial com deficientes mentais e afásicos.

Em 1976, surge o livro de Ritvo sobre o Autismo e nele se fala em um problema de desenvolvimento, salientando-se que muitos estudos referiam-se às crianças autistas como possuidoras de déficit cognitivo. No entanto, a despeito de considerar que o Autismo é fenomenologicamente bastante diferente das formas de esquizofrenia do adulto, apontava que vários autores postulavam uma espécie de "continuum", que se estenderia das formas infantis às formas encontradas no adulto.

Sua caracterizaçào, pelo próprio Ritvo, é entào feita a partir da idade de aparecimento (já ao nascimento) e por suas características comportamentais, representadas por:

- Distúrbios de Percepçào (hipo/ hiperatividade aos estímulos, devido a falhas na modulaçào dos inputs sensoriais, distorção da hierarquia de preferência dos receptores e déficit no uso do input sensorial para discriminar em ausência de feed-back das respostas motoras);

- Distúrbios de desenvolvimento, principalmente nas seqüências motora, de linguagem e social;

- Distúrbios do relacionamento social, caracterizados por pobre contato através do olhar; ausência de sorriso social; ausência de movimento antecipatório (no bebê); aparente aversào ao contato físico; tendência a relacionar-se com partes da pessoa; desinteresse em jogos, ansiedade estranha e exagerada;

- Distúrbios da fala e da linguagem, que se estendem desde um mutismo até a ecolalia e a inversào pronominal;

- Distúrbios da motilidade, observados através da atitude estranha e bizarra, como maneirismos e estereotipias, principalmente de màos e dedos.

A escola francesa, fiel à concepçào do que foi o termo "psicose", remete a um defeito de organizaçào ou a uma desorganizaçào da personalidade (Housel,1991), enquadrando o Autismo dentro dessa categoria, do mesmo modo que a nona revisào da CID (Misés, 1990; OMS).

Por outro lado, o DSM III-R (APA,1989); o DSM IV (APA,1994) e a própria CID 10 (OMS, 1993) dentro de uma abordagem eminentemente descritiva, com sinais e sintomas comportamentais, 
portanto, bastante distinta de uma visào) compreensiva do quadro, coloca o Autismo Infantil dentro dos distúrbios globais de desenvolvimento das habilidades de comunicaçà verbal e nào verbal e de atividade imaginativa.

Os déficits autísticos, conforme relatamos até o presente, estào relacionados a um déficit crônico nas relaçòes sociais, descritos em todos os trabalhos de Kanner (1943, 1949, 1956, 1968 , 1973), bem como nos de Ritvo (1976) e mesmo nas atuais classificaçoes do DSM III-R (APA,1989); DSM IV (APA,1994), da Francesa de Distúrbios Mentais (Misés, 1990) ou na CID 10 (OMS, 1993).

Duas teorias sào, então, passíveis de tentar esclarecer o fenômeno. Uma das propostas de compreensão do cléficit social do autismo, reporta-se à teoria afetiva, originalmente sugerida por Kanner (1943), inclusive a partir do título de seu trabalho "Distúrbios Autísticos do Contato Afetivo". Várias versòes foram elaboradas no decorrer do tempo, sendo) interessante destacar a de Hobson (apud Baron-Cohen,1988), com seus quatro grande axiomas, a saber:

I. Crianças autistas possuem falhas constitucionais de componentes da açào e reaçào, necessários para o desenvolvimento das relaçoes pessoais com o outro que envolvam afeto;

II. As relaçòes pessoais sào necessúrias para a constituiçào do mundo próprio e do mundo exterior;

III. Os déficits das crianças autistas na participaçào da experiência social intersubjetiva têm dois resultados especialmente importantes:

- déficit relativo ao reconhecimento de outras pessoas, como portadoras de sentimentos, pensamentos, intençòes e desejos próprios;

- déficit severo na capacidade para abstrair, sentir e pensar simbolicamente;
IV. Grande parte das inabilidades de cogniçào e linguagem das crianças autistas pode refletir déficits, que têm íntima relaçào com o desenvolvimento afetivo e/ou déficits sociais dependentes da possibilidade de simbolizaçào.

Contrapondo-se à teoria afetiva, Baron-Cohen $(1988,1990,1991)$ e Frith (1988) propoem uma teoria cognitiva para o autismo.

Como ponto central, essa visào também considera que a dificuldade central da criança autista é a impossibilidade de compreender estados mentais de outras pessoas.

Essa habilidade tem sido chamada, por esses autores, de teoria da mente porque envolve o conceito da existência de estados mentais, utilizados para explicar ou prever o comportamento de outras pessoas.

A teoria cognitiva sugere que no autismo, a capacidade de meta-representaçoes encontra-se alterada, fazendo com que os padroes de interaça social sejam alterados.

Assim, quando o DSM IV ou a CID 10 preferem pensar e classificar o Autismo Infantil como um Distúrbio de Desenvolvimento, partem da premissa de que sula gênese, sob o ponto de vista compreensivo, é uma alteraçào cognitiva. Da mesma maneira, quando a CID 9 ou a Classificaçào Francesa de Distúrbios Mentais (Misés,1990) o agrupam dentro dos quadros de Psicoses da Infância, o fazem dentro de um sistema referencial que considerará nào "a quebra" das noçòes do Eu e do Mundo, mas sim a "não-estruturaçào" dessás categorias que serào fundamentais na conceituaçào dos quadros psicóticos.

Dentro dessa concepçào, podemos partir do pressuposto que o ser humano, por meio de uma indiferencia(cào inicial, gradativamente constitue suas categorias de Eu, Espaço e Tempo, através de suas experiências e da 
relaçào que estabelece com o meio circunjacente. Essa relação é impulsionada por movimentos afetivos em suas mais diversas formas e instrumentalizada por mecanismos cognitivos. A partir dessas dificuldades no relacionamento com o ambiente circunvizinho, quer a partir de déficits de tipo afetivo, quer a partir de uma instrumentalizaçào cognitiva deficitária, instaura-se o Autismo e seu cortejo sintomatológico.

\section{O DIAGNÓSTICO PSIQUIÁTRICO}

O termo "psicose", segundo Houzel (1991), remete-nos a um defeito de organizaçào ou a uma desorganizaçào da personalidade, constituindo-se, portanto, em um distúrbio maciço do sentido da realidade.

Partinclo desse parâmetro, foram descritos, até meados dos anos 40, vários quadros com evoluçào demencial, enquadrados nosograficamente dentro do grupo das psicoses infantis. Entretanto, a inclusão do autismo nesse grupo variou e varia de acordo com as escolas psiquiátricas consideradas.

Nos Estados Unidos, segundo Lebovici (1991), foi Margareth Mahler quem estudou primariamente as psicoses infantis, fazendo delas um modelo para o estudo do desenvolvimento da criança. Descreveu, assim, as psicoses autísticas e simbióticas, bem como os estados autístico e simbiótico de desenvolvimento.

A Psiquiatria Inglesa, mais fiel ao conceito de Esquizofrenia Infantil, estabelece uma descriçào da síndrome confundida com o autismo realizada por Creack, em 1961, a partir de uma escala de 15 pontos, dos quais 9 deveriam ser positivos para o estabelecimento.

Dessa maneira, nos países anglosaxões, o termo autismo vai incorporar basicamente o conjunto das psicoses na criança, ficando a esquizofrenia reservada a casos de ocorrência pré-puberal, com a sintomatologia similar a da esquizofrenia do adulto, se usarmos os padrões diagnósticos do DSM IV. Nessa classificaçào, o autismo será enquadrado no grupo dos distúrbios globais do desenvolvimento, considerando-se como seu ponto básico uma constelaçào deficitária a nível cognitivo, lingüístico e motivacional (Hobson, 1991).

Por outro lado, para a escola francesa, o autismo é uma entidade dentre as psicoses da criança (Lebovi(i,1991). Assim sendo, diferenciar-se-ão diversos quadros de psicoses na infância, que terào importância em relaçào à nosografia estudada. Desse modo, o termo psicose precoce é utilizado para os quadros que se instalam na primeira infância, a exemplo do autismo infantil, enquanto o de esquizofrenia é aplicado a quadros de desestruturaçào de personalidade após fase de desenvolvimento estável. Nesse trabalho, foi de fundamental importância a delimitação dos quadros englobados dentro do conceito de "distúrbios abrangentes de desenvolvimento", a partir das descriçoes mais conhecidas e utilizadas.

Temos, assim, que considerar os seguintes quadros, descritos por diferentes autores:

a) Síndrome de Asperger - grupo primariamente descrito por Asperger, em 1944, sob a designação de Psicopatia Autística: É um quadro caracterizado por déficit na sociabilidade, interesses circunscritos, déficit de linguagem e de comunicação (Bowman,1988; Szatamari,1991).

A relaçào entre Autismo e Síndrome de Asperger é discutível, com a possibilidade de ser enquadrada dentro (lo espectro autístico descrito por Wing (1988)

b) Com características que pode- 
mos considerar superpostas à Síndrome de Asperger, a Psiquiatria Francesa, através de sua Classificaçào (Misés, 1990) descreve as chamadas Desarmonias de Evoluçào. Incluídas nas psicoses deficitárias, bem descritas por Lang (1978), referem-se a crianças com evoluçào atípica, clando a impressào de desarmonia, principalmente em relaçào à linguagem, onde a pobreza sintática contrasta com a preciosidade de vocabulário (Lebovici,1991). Observa-se dificuldades no uso da primeira pessoa pronominal, fato esse compreendido como distúrbio na evoluçào da própria identidade. Vêem-se, ainda, sinais neuróticos e atitudes paradoxais, tais como atividades rituais, estereotipias e comportamentos bizarros. Esse quadro é avaliado por Lang (1978) como fronteiriço, denominando-o de parapsicose.

A nosso ver, esses dois conjuntos possuem grancle semelhança, caracterizando-se como "autistas-like", porem com as desarmonias de evoluçào se constituindo em um quadro nosográfico de maior amplitude, com a tônica maior centrada no desenvolvimento discrepante das diversas funçòes, com etiologias, evoluções e tratamentos diversos. Eles parecem caracterizar um rendimento cognitivo bom e na descrição das desarmonias de evoluçào, encontramos mecanismos intrapsíquicos que lembram as psicoses infantis, sob o ponto de vista de sua compreensibilidade.

Paralelamente aos quadros de deficiência mental, encontramos os chamados Transtornos Desintegrativos, incluindo-se aí aqueles problemas onde existe um desenvolvimento normal ou próximo ao normal, nos primeiros anos de vida, seguido por baixa nos padròes sociais e de linguagem, conjuntamente com alteraçòes nas emoçoes e relacionamento (Corbett,1987). Habitualmente, a diminuiçào da sociabilidade e da linguagem dura um pequeno perío- 
do, sendo posteriormente, acompanhada pelo aparecimento de hiperatividade e estereotipias. Em muitos casos, há comprometimento intelectual, embora, este nào seja obrigatório, da mesma forma que pode nào existir dano cerebral detectável.

No CID 9, as psicoses desintegrativals incluem as antigas demências de Heller, mas excluem o autismo e a esquizofrenia infantil.

Os critérios diagnósticos do IDSM IV (APA, 1994), pressupòem:

a- Desenvolvimento aparentemente normal, pelo menos clurante os dois primeiros anos após o nascimento, manifestado pela presença de comunicação verbal e não-verbal, relacionamentos sociais, jogos e comportamento adaptativo apropriados à idade.

b- Perda clinicamente significativa de habilidades já adquiridas (antes dos 10 anos), em pelo menos duas das seguintes áreas:

1) linguagem expressiva ou receptiva;

2) habilidades sociais ou comportamento adaptativo;

3) controle intestinal ou vesical;

4) jogos;

5) habilidades motoras.

c- Anormalidades de funcionamento em pelo menos duas das seguintes áreas:

1) prejuízo qualitativo na interaçào social;

2) prejuízos qualitativos na comunicaçào;

3) padròes restritos, repetitivos ou estereotipados de comportamento, interesses ou atividades, incluindo estereotipias motoras e maneirismos.

Finalmente, ainda dentro do grupo dos Transtornos Globais do Desenvolvimento, encontramos a síndrome de Rett, associada a retardo mental profundo, afetando especificamente o sexo feminino e com o desenvolvimento de múltiplos déficits específicos, também após um período de funcionamento normal clurante os primeiros anos de vida.

O uso das màos é limitado, com o aparecimento de estereotipias características (como o movimento semelhante ao de lavar as màos), podendo ocorrer uma diminuiçào no crescimento do perímetro cefálico e a presença freqüente de síndrome convulsiva.

Outros sinais passíveis de serem encontrados sào: a hiperventilaçào episódica, as anormalidades eletroencefalográficas e a deterioraçào neurológica lenta, com aparecimento de rigidez e diminuiçào da mobilidade (Rutter,1994).

Finalizando, podemos dizer que mesmo considerando os Transtornos Globais do Desenvolvimento, um agrupamento bastante heterogêneo de quadros clínicos, acreditamos que, gradativamente, com os novos conhecimentos advindos de novas técnicas de pesquisa, e, principalmente, do melhor conhecimento dos mecanismos mentais, possamos abordar, de maneira cada vez mais eficaz, essa questào tão complexa, quer sob o ponto de vista diagnóstico, quer do terapêutico. 


\section{REFERÊNCIAS BIBLIOGRÁFICAS}

BARON-COHEN, S. (1988). Social and pragmatic deficits in Autism: Cognitive or Affective? In: Journal of Autism Develop Disord., v.3, n.18, p. 379-401.

BARON-COHEN, S. (1990). Autism, a specific cognitive disorder "mind-blindness". In: International Review of Psychiat., n.2, p. 81-90.

BARON-COHEN, S. (1991). The development of a theory of mind in autism: deviance and delay? In: Psychiat. Clin. North Am., v.14, n.1, p. 33-52.

BOWMAN, E. P. (1988). Asperger's syndrome and autism: the case for a connection. In: British fournal of Psychiat., v.152, n.3, p. 377-382.

CORBETT, J. (1987). Development, desintegration and dementia. In: Journal Ment. Defic. Res., n. 31, p. 349-356.

FRITH, U. (1988). Autism possible clues to the underlying pathology. Psychological facts. In: Wing, L. Aspects of autism: biological research. London: Royal College of Psychiatrists \& The National Autistic Society, p. 19-30.

GILBERG, C. $(1990)$. Autism and pervasive developmental disorders. In: Journal of Child Psycholo Psychiat., v. 31, n. 1, p. 99119.

HOBSON, R. P. (1991). What is autism? In: Psychiat. Clin. North Amer., v.14, n.1, p. 1-18.

HOUZEL, D. (1991). Reflexòes sobre a definiçào è a nosografia das psicoses infantis. In: MAZET, P., LEBOVICI, S. (orgs.). Autismo e Psicoses da Criança. Porto Alegre: Artes Médicas, p. 31-50.

KANNER, L. (1943). Autistic disturbances of affective contact. In: Nerv. Child, n. 2, p. 217-250.

KANNER, L. (1949). Problems of nosology and psychodinamics in early infantile autism. In: American Journal Ortbopsychiat., n. 19, p. 416-426.

KANNER, L. (1956). Early infantile autism, 1943-1955. In: Am. J. Orthopsychiat., n. 26, p. $55-65$.
KANNER, L. (1968). Early infantile autism revisited. In: Psychiat. Digest, n. 29, p. 17-28.

KANNER, L. (1973). Follow-up study of eleven autistic children originally reported in 1943. In: KANNER, L. (org.). Childhood Psychosis: initial studies and new insights. New York: John Wiley \& Sons.

I.ANG, J. L. (1978). Nas fronteiras da psicose infantil. Rio de Janeiro: Zahar.

LEBOVICI, S., I)UCHE, D. J. (1991). Os conceitos de autismo e psicose na criança. In: MAZET, P., LEBOVICI, S. (orgs.). Autismo e psicoses da criança. Porto Alegre: Artes Médicas.

Manual de Diagnóstico e Fstatística de Distúrbios Mentais (DSM III-R). (1989). São Paulo: Manole.

Manual de Diagnóstico e Estatística de Distúrbios Mentais (DSM IV). (1994). Porto Alegre: Artes Médicas.

MISÉS, R. (1990). Classification française de troubles mentaux de l'enfance et de l'adolescente. Neuropsychiatric de l'enfance, $v$. 38, n. $10 / 11$, p. 523-539.

PARNAS, J., BOVET, P. (1991). Autism in schizophrenia revisited. Comprehensive Psychiatry., v. 32, n. 1, p. 7-21.

RI'TVO, E. R. (1976). Autism: diagnosis, current research and management. New York: Spectrum.

RUTTER, M., TAYLOR, E., HERZOV, L. (1994). Child and adolescent psychiatry. Oxford: Blackwell.

SZATAMARI, P. (1991). Asperger's syndrome: diagnosis, treatment and outcome. Psychiat. Clin. North Amer., v. 14, n. 1, p. 8193.

WHO (1993). Classificaçào Internacional das Doenças. Porto Alegre: Artes Médicas.

WING, L. (1988). The autistic continuum. In: Wing, L. (org.) Aspects of autism: biological research. London: Royal College of Psychistrists \& The National Autistic Society, p. 5-8 